\title{
MORNAS ERAM AS NOITES OU VIAGEM AO REDOR DE CABO VERDE COM DINA SALÚSTIO
}

\author{
WARM WERE THE NIGHTS OR VOYAGE \\ AROUND CAPE VERDE WITH DINA SALÚSTIO
}

Demétrio Alves $\mathrm{Paz}^{*}$

\section{RESUMO}

O presente trabalho tem por objetivo analisar o simbolismo presente em Mornas eram as noites, de autoria da cabo-verdiana Dina Salústio, e propor uma tipologia temática para os contos, relacionando-a ao tópico da viagem. Nas trinta e cinco narrativas, observamos que há temas comuns em várias delas, tais como: partida e regresso; a condição feminina; relações familiares; pobreza e necessidade; memória; violência (doméstica ou social). Da mesma forma, notamos que há figuras femininas diferenciadas, representando um amplo apanhado de todas as classes sociais e de diferentes idades. A grande maioria das histórias é narrada em primeira pessoa, o que aproxima o leitor e também funciona como uma espécie de pedido de cumplicidade por parte das narradoras. Percebemos que a noite surge em muitos enredos como um símbolo de transformação, tendo em vista o subtítulo da obra: “... De como elas se entregam aos dias". Igualmente, constatamos a dubiedade do subtítulo que pode tanto referir-se às noites (do título) como às personagens femininas representadas nos contos.

PALAVRAS-CHAVE: Conto; Simbolismo; Viagem.

\section{ABSTRACT}

The purpose of this essay is to analyze the symbolism in the book Mornas eram as noites (Warm were the nights), by Cape-Verdean writer Dina Salústio, and propose a thematic typology to the short stories, relating it to the topic of voyage. In the thirty-five narratives, we note that are common themes in some of them, such as: leaving and returning; the female condition; family relations; poverty and necessity; memory; (domestic and social) violence. In the same way, we perceived that are differentiated female 
characters, representing a broad view of all social classes and different ages. Most of the stories are narrated in the first person, which makes the reader closer to the narrator and functions as a call for an accomplice to the reader by the narrator. We also observed that the night appears in many plots as a symbol of transformation, as seen in the subtitle of the work: “... De como elas se entregam aos dias" (Of how they deliver themselves to the days. Likewise, we can see the dubiety in the subtitle that can refer not only to the nights (in the title) but also to the female characters presented in the stories.

KEYWORDS: Short Story; Simbolism; Voyage.

\section{UMA DESCOBERTA OCASIONAL: DINA SALÚSTIO}

Italo Calvino, em Por que ler os clássicos (1994, p. 16), aconselha a: inventar para cada um de nós uma biblioteca ideal de nossos clássicos; e diria que ela deveria incluir uma metade de livros que já lemos e que contaram para nós, e outra de livros que pretendemos ler e pressupomos possam vir a contar. Separando uma seção a ser preenchida pelas surpresas, as descobertas ocasionais.

Seguindo à risca a sugestão de Calvino, uma das minhas descobertas ocasionais foi a obra Mornas eram as noites, da escritora cabo-verdiana Bernardina de Oliveira Salústio, mais conhecida como Dina Salústio. Ela nasceu na ilha de Santo Antão em 1941, trabalhou em Angola, Cabo Verde e Portugal, é assistente social, jornalista e professora, além de escritora. Autora das obras: Mornas eram as noites (1994), A Louca de Serrano (1998), A Estrelinha Tlim, Tlim (1998), O que os olhos não veem (2002) e Filha do Vento (2009). Recebeu o primeiro prêmio de literatura infantil de Cabo Verde em 1994, o terceiro prêmio de literatura infantil dos Países Africanos de Língua Oficial Portuguesa (PALOP) em 1999. Pouco conhecida e divulgada, a sua obra é pesquisada por poucos, fato que dificulta ainda mais os estudos, pois há pouca fortuna crítica. A pesquisadora que mais se dedicou ao estudo da autora cabo-verdiana é Simone Caputo Gomes.

\section{A FICÇÃO EM PROSA DE CABO VERDE}

$\mathrm{Na}$ década de 30, um grupo de escritores de Cabo Verde entrou em contato com a literatura brasileira contemporânea, que passou a ser uma influência nas obras literárias a partir de então. As revistas Claridade (1936) e Certeza (1944), o Suplemento Cultural (1958), entre outros, ajudaram a difundir os textos literários produzidos pelos autores do país (FERREIRA, 1987; LARANJEIRA, 1995, SANTILLI, 2007). Nos anos 40, com 
a chegada de Manuel Ferreira ao arquipélago, o neorrealismo português é introduzido por meio da revista Certeza, passando também a produzir efeitos sobre a escrita literária no país (LARANJEIRA, 1995). Portanto, as duas principais revistas tiveram influências distintas: Brasil e Portugal em menos de uma década. Entretanto, os pressupostos estéticos e literários estrangeiros foram adaptados à realidade da nação.

Aliás, durante quase 50 anos, as revistas, os suplementos literários e o boletim oficial tiveram reflexos na vida cultural e ajudaram a consolidar um sistema literário, talvez o primeiro a ser, de fato, estabelecido nos países africanos de língua portuguesa. A partir dos anos 30, surge "uma nova maneira de encarar a realidade cabo-verdiana e, consequentemente, uma nova maneira de exprimi-la linguisticamente, criando-se uma diferente e atualizada linguagem artística." (FERREIRA, 1987, p. 43).

Há uma tradição narrativa que inicia com Baltasar Lopes e Manuel Lopes, passa por Teixeira de Sousa, Manuel Ferreira, António Aurélio Gonçalves, Luís Romano, Teobaldo Virgínio, Gabriel Mariano, Orlanda Amarilis e tem continuidade em Germano de Almeida, Dina Salústio e outros escritores ligados à revista Ponto e vírgula (FERREIRA, 1987; LARANJEIRA, 1995, SANTILLI, 2007).

Ao tratar da obra de Manuel Ferreira e suas linhas temáticas, Maria Aparecida Santilli (2007, p. 182) destaca que o autor: "adotou causas/ temáticas típicas cabo- verdianas, como o sentimento de insularidade e o consequente desejo de evasão, a seca, a fome, [...] a miséria como agente de desagregação social." A afirmação serve, também, para boa parte da ficção produzida no país depois da revista Claridade.

\section{DESLOCAMENTO E SIMBOLISMO}

O objetivo do presente ensaio é analisar tanto os símbolos que surgem ao longo da obra (noite, mar, ilha, maternidade e morte), propondo uma tipologia com uma divisão para os contos, quanto relacioná-los à temática da viagem, entendida aqui como um deslocamento em busca de (re)conhecimento de Cabo Verde e dos diferentes problemas apresentados nas narrativas curtas de Dina Salústio. Nas trinta e cinco narrativas, observamos que há temas comuns em várias delas, tais como: partida e regresso; a condição feminina; relações familiares; pobreza e necessidade; memória; violência (doméstica ou social).

A viagem sempre foi um tema frequente na literatura, fornecendo diversas obras-primas. O mais antigo épico do qual se tem notícia, A epopeia de Gilgamesh, é uma narrativa de viagem, em busca da imortalidade. Também Odisseu em sua Odisséia, Enéas na Eneida, Dante pelo inferno, purgatório e paraíso têm de viajar. A viagem é indispensável para o amadurecimento da personagem que necessita se deslocar, tanto geográfica quanto interiormente, em busca de autoconhecimento. 
Nos contos de Mornas eram as noites, percebe-se que "A viagem torna-se iniciação e a aprendizagem, a própria vida. A viagem representa metaforicamente a vida e, paralelamente, as suas etapas, os encontros, os erros da caminhada presentificam-na metonimicamente." (LAMAS, 1997, p. 448). Dessa forma, a obra é rica em diferentes representações de viagens, concebendo que nem todo deslocamento é exterior, podendo se dar no interior da personagem.

Cecília Meireles (1999), num texto conciso intitulado "Roma, turistas e viajantes", estabelece uma diferença entre o turista e o viajante. O primeiro é uma criatura feliz, dispersiva (sua curiosidade é superficial), andando com sua máquina fotográfica, guia, vocabulário reduzido; velocidade é a sua palavra, pois faz tudo rapidamente. Os olhos do turista são a sua máquina, pois não mais se contenta em apreciar com os próprios olhos a paisagem. O turista é um passageiro, visto que passa e pode voltar um dia, mas o caminho percorrido ficou para trás, lembrado apenas pelas fotos. Além disso, ele é um comprador, compra o que pode e prova, por meio de fotografias, que esteve ali; e com suas pechinchas, o que há de bom para ser comprado.

O viajante não é muito feliz, mas está lá por amor às coisas. É um ser curioso, pois quer descobrir tudo ao seu redor. Conhecedor da língua, costumes e cultura (literatura, história, filosofia), procura em todas as coisas um significado. Seu olhar e sua memória lhe bastam, pois contempla a tudo com paixão e respeito. $\mathrm{O}$ olhar é lento, porém analista. $\mathrm{O}$ viajante não apenas vê, observa, analisa, ele também sente, pensando no passado e no que o futuro reserva. Pensa naqueles que estiveram ali antes e nos que ali passarão. Ousando complementar a proposta de Cecília Meireles, diria que Dina Salústio é uma espécie de mapa do viajante, pois conhece e compreende muito bem o que nos apresenta. Nuno Júdice (1997, p. 621) afirma que

a descoberta do espaço da viagem - é vivida do mesmo modo por aquele que lê e aquele que viaja, neste gênero literário em que a verosimilhança, o efeito de realidade, o mimetismo linguagem-mundo, fazem parte da condição sine qua non de testemunho que o texto deve ter para convencer o seu leitor a respeito daquilo que se conta.

Como se pode ver, Júdice ressalta dois papéis: o do escritor e o do leitor. Está-se diante de uma relação entre narrador e narratário, cujo pacto narrativo pressupõe a anuência entre ambos, numa cumplicidade ou, pelo menos, empatia sobre o que se lê.

Fernando Cristóvão (2002) estabelece uma tipologia para a literatura de viagens. Entre as categorias por ele apresentadas, a presente nos contos de Mornas eram as noites enquadra-se na de viagem erudita. Não há na obra a realização de feitos grandiosos, mas "a partilha do saber e da solidariedade social” (CRISTÓVÃO, 2002, p. 48). 
Nos contos, as narradoras preocupam-se com a realidade das ilhas, revelando um forte humanismo, na busca pela compreensão dos costumes, da cultura e das histórias ao longo de seu itinerário. A viagem é de (re)descoberta ou de apresentação da sua terra e de seu povo. Em Viagens na minha terra, por exemplo, Almeida Garrett realiza uma peregrinação de descoberta de uma região de seu país. Pode-se dizer que Dina Salústio efetua quase o mesmo, com a diferença de que ela, de fato, conhece o país, por isso a noção de (re)descobrimento.

No título da obra já há duas referências simbólicas. A primeira refere-se a um gênero musical: a morna. Simone Caputo Gomes (2006, p. 99) elucida que morna é a

modalidade musical típica de Cabo Verde que veicula a poesia oral. Tradicionalmente canto de mulher, o entendimento do lugar cultural da morna no mundo cabo-verdiano pode derramar outras luzes sobre a significação do título: "música eram as noites" é uma leitura para Mornas eram as noites. Música de mulheres, em que a mulher é a peça principal.

No caso do livro de Dina Salústio, as mulheres não são só a principal peça, como a que adquire voz, tendo em conta que a grande maioria das histórias é narrada em primeira pessoa por elas. Ainda em relação às mornas, Maria Teresa Salgado (2008, p. 38) percebe o gênero como "verdadeiras crônicas vivas e expressivas da vida do cabo-verdiano, podendo exprimir a dor, a alegria, a nostalgia, os problemas existenciais, a esperança”, temas que aparecem em diferentes contos do livro. Assim, o gênero musical, como outras formas artísticas, também é uma representação da identidade do país.

A segunda, a noite, é "relacionada ao feminino e o inconsciente" (CIRLOT, 1984, p. 409). Lurker (1997) vê nela o horário propício à transformação, pois antecede o dia que revela/mostra. Para Chevalier e Gheerbrant (2000, p. 640),

A noite simboliza o tempo das gestações, das germinações, das conspirações, que vão desabrochar em pleno dia como manifestação de vida. Ela é rica em todas as virtualidades da existência. [...] Como todo símbolo, a noite apresenta um duplo aspecto, o das trevas onde fermenta o vir a ser, e o da preparação do dia, de onde brotará a vida.

Portanto, ao relacionar os dois símbolos presentes no título, a identidade do país é gestada aos poucos, superando problemas e tendo esperança no novo dia que surgirá, trazendo transformações. O conhecimento e a revelação dessas mudanças dão-se por meio da viagem. Apresentarei agora a tipologia, dividida em seis categorias.

O primeiro grupo de narrativas tem como tema a partida e o regresso às ilhas: sair e voltar para Cabo Verde, de alguma forma, transforma a personagem, mas o regresso dá-se pela saudade ou apego à terra. 
Em "Uma viagem de saudades", um narrador homodiegético introduz uma história que ouviu e a reproduz. Dois jovens apaixonaram-se, mas ela teve de fazer uma viagem para conhecer o pai. Originalmente, o casal ficaria separado por somente três meses, porém o retorno dela demorou 30 anos. Agora, no regresso a ilha Brava, três décadas depois, ela ainda se sente a mesma jovem de 17 anos.

No exterior, ela teve uma vida: "casara em França, foi feliz, infeliz, viveu e morreu como todos nós nesses anos; mas era como se o tempo lhe tivesse poupado o coração; como se a esperança não tivesse sofrido um lanho que fosse, enquanto estivera ausente." (SALÚSTIO, 1999, p. 20) Ele, muito pelo contrário, apenas sobrevivera durante o período do afastamento, de tal forma que o "moço bonito, branco, de cabelo fino" (SALÚSTIO, 1999, p. 19) deu lugar a um homem "[...] atarracado pelos anos e pelas gorduras, careca, avermelhado pelo grogue.” (SALÚSTIO, 1999, p. 20).

O simbolismo antitético da ilha ilustra muito bem o conto. Ela, que saiu e retornou, representa a "consciência e vontade" (CIRLOT, 1984, p. 307), a mudança, porém restaram tanto a saudade quanto a lembrança de um tempo idílico. Ele, que permaneceu, ficou isolado, sozinho, morto para a vida. A viagem, a saída da terra natal, alterou quase tudo na vida da mulher, exceto a sua memória da paixão juvenil, com o devido idealismo típico da idade. A personagem parece alheia às mudanças que podem ter ocorrido em três décadas, como se nada fosse alterado pelo passar do tempo. A vida que ela teve no exterior, com todas as oportunidades, fez com que ela esquecesse como era a realidade de sua terra natal.

Outros contos que pertencem à mesma categoria: "Ponto final", “...Ou quando Santo Antão é apenas silêncio”.

A condição feminina é o segundo e mais numeroso grupo. Nas histórias há o reconhecer-se como mulher, ter consciência de seu papel e de sua sexualidade numa sociedade onde os homens têm todas as liberdades. Devido não só ao fato de a escritora ser mulher, mas também ao fato de representar mulheres de diferentes estratos da sociedade (GOMES, 2013, p. 53), essa é a temática predominante na obra. Exemplos da mesma temática: "Mãe não é mulher", "Please come back to me", "A oportunidade do grito", "E porque havia de não gostar", "Forçadamente mulher, forçosamente mãe", "O conhecimento em debate", "Álcool na noite", "O que é isso de liberdade?", "Os caminhos insondáveis do profeta", "Conversa de comadres”.

Em "Liberdade adiada”, uma mulher, cansada da vida que leva (carregar água, cuidar dos filhos), pensa primeiro em suicidar-se e depois em ir embora, abandonando a vida miserável que tem. $O$ início do conto, ao referir-se ao seu cansaço - "A barriga, as pernas, a cabeça, o corpo todo era um enorme peso" (SALÚSTIO, 1999, p.7) -, lembra muito a descrição de um parto. No seu caso, os filhos já existem, provavelmente é o nascimento de sua independência: "Não. Não voltaria para casa." (SALÚSTIO, 1999, p. 7). 
Do mesmo modo, em seguida, emerge o vislumbre de um suicídio: "O barranco olhava-a, boca aberta, num sorriso irresistível, convidando-a para o encontro final." (SALÚSTIO, 1999, p. 8) Ela cogita o suicídio, afinal, "nunca teve nada para perder." (SALÚSTIO, 1999, p. 8) Uma vida de sacrifícios, de trabalho pesado, de sonhos adiados ou renegados transformou-a em alguém sem muitas perspectivas. A sua existência resumia-se aos filhos e às lides domésticas. Contudo, foi a lembrança deles que a fez adiar mais uma vez seus desejos, "deixando o barranco e o sonho de liberdade para trás.” (SALÚSTIO, 1999, p. 8).

Mais uma vez é um narrador homodiegético que nos conta a história, como uma espécie de viajante em busca do conhecimento. Pode-se dizer que a morte, nessa narrativa, é um símbolo antitético, vista como a possibilidade de "suprema libertação" (CIRLOT, 1984, p. 389). Assim, ao refletir e pensar novamente nos filhos, ela desiste de sua independência e de suas fantasias pela família.

As relações familiares são o terceiro grupo, no qual a estrutura social é representada e interfere no enredo. Exemplos: "Um encontro para depois", "Ligação à noite".

Em "Filho és, pai serás", a narradora (autodiegética) lembra-se de sua mãe e da educação rígida recebida, assim como dos "provérbios ditos em português que, no contexto quotidiano crioulo, adquiriam um peso e um estatuto que nos amedrontavam." (SALÚSTIO, 1999, p. 23) Está-se diante de um dado importante, pois a língua portuguesa é usada como instrumento de poder. O uso do idioma do ex-colonizador por parte da mãe, em um contexto específico, adquire uma força maior do que a agressão física sofrida no passado pela narradora.

No dia das mães, ela recebe a ligação de sua genitora que, ironicamente, lembra-lhe que dia é. Ela se despede proferindo um de seus provérbios. A narradora sente-se mal, pois se esqueceu da data e de ligar para a mãe. Um de seus filhos liga e a parabeniza. Para se vingar, como a mãe fez com ela, liga para o outro filho, que se esqueceu de parabenizá-la, e o ataca, dizendo um dos provérbios preferidos de sua mãe: "Filho és, pai serás, assim como fizeres, assim acharás.” (SALÚSTIO, 1999, p. 23)

O filho, com medo da praga, retorna a ligação após um tempo e tudo é esclarecido. A narradora finaliza: "A mesma sensação que eu sentia em criança, reconheci, pensando em coisas como filhos, educação, famílias. E na minha mãe." (SALÚSTIO, 1999, p. 25)

No conto, a maternidade é a "raiz de todas as coisas" (CIRLOT, 1984, p. 376), sejam boas ou ruins. A educação recebida pela filha não foi a mesma que ela deu aos seus filhos. Percebe-se que há uma intimidade entre mãe e filhos que não existe entre mãe e filha.

Pobreza e necessidade fazem parte do quarto grupo de narrativas, em que as condições de vida dos mais necessitados são mostradas. Exemplos: "Ele queria tão pouco", "Um ilegítimo desejo", "A indústria de tambores", "Tabus em saldo", "Traição do tempo". 
Em "Natal", "Três mocinhos semi-esfarrapados entram" (SALÚSTIO, 1999, p. 68) numa loja e observam tudo o que não podem comprar. A narradora (autodiegética) os observa e vê neles o verdadeiro espírito do Natal: o desejo, a vontade, a espera; ainda que saibam que aquilo não lhes pertence, eles não perdem a oportunidade de tocar os brinquedos, "cada um vivendo o sonho de uma viagem, a aventura de uma corrida." (SALÚSTIO, 1999, p. 68)

Outros compradores reclamam dos preços e do Natal. Para eles, a celebração deveria acabar. A narradora discorda, para ela a comemoração é boa, o período é bom, o que é ruim é o que fizeram com o Natal, transformando-o num comércio; por isso, recorda:

É bom haver Natal. É bom escrever aos amigos e dizer-lhes que estão comigo o tempo todo, apesar de meu silêncio. É bom haver Natal e poder dizer-te que tenho saudades tuas, que te amo e que te queria abraçar forte. É bom haver Natal, quando não é época de sacrifícios e angústias e dívidas, para se manter uma ridícula aparência de sucesso. (SALÚSTIO, 1999, p. 68)

Ela também se preocupa com os meninos, tal como uma mãe: “Onde está a família deles? Já terão comido hoje?” E faz conjecturas: “Só sei que estão a viver mais um Natal. O seu Natal, tecido com olhares e imaginação: um Natal de espreita." (SALÚSTIO, 1999, p. 69)

Os clientes, ao perceberem as crianças dentro da loja, ficam assustados e a vendedora os expulsa. Os adultos esqueceram-se das crianças que uma vez já foram e não demonstram empatia alguma pelos necessitados. A narradora, mais uma vez, reflete sobre a comemoração: "Talvez o natal passasse a ser mais humano, mais de compromisso, porque não artificial." (SALÚSTIO, 1999, p. 69) E os meninos "Tranquilamente saem, em busca de outras lojas de sonhos.” (SALÚSTIO, 1999, p. 69)

Memória é o quinto grupo: o passado torna-se significativo no presente por meio das lembranças, que geram reflexões. Exemplos: "Campeão de qualquer coisa", "Eram todas finalistas", "Sem remorsos".

Em “Onde está a verdade?”, a narradora (autodiegética), ao retornar à praia de Escorralete, relembra um tio, que naquela época parecia ter três metros de altura, que dava presentes, que conferia os cadernos, que fazia perguntas e que sempre se mostrava interessado no que as crianças estavam aprendendo. O parente a incentivou a estudar e saber mais. Após crescer, ela descobre que o tio mal chegava a ter $1,8 \mathrm{~m}$ de altura. Mas a grande e reveladora descoberta foi "ver aquela imensidade de homem privado de uma coisa tão simples como a escrita, que nós, desde crianças, dominávamos, quase que instintivamente." (SALÚSTIO, 1999, p. 17)

A revelação, por meio de uma coincidência de encontrar o tio solicitando a mãe que escrevesse uma carta aos filhos, serviu para refletir sobre o que significava a verdade. O estranhamento do local visitado novamente indica o simbolismo do mar como "agente transitivo e mediador 
entre o informal (ar, gases) e o formal (terra, sólido) e, analogicamente, entre a vida e a morte. O mar, os oceanos, são considerados a fonte da vida e o final da mesma." (CIRLOT, 1984, p. 372) Assim, o contraste entre a informalidade da falta de instrução do parente e a formalidade pela instrução da narradora desencadeia nela o questionamento sobre a verdade.

O tio, provavelmente analfabeto, sempre demonstrou respeito ao estudo, sem, contudo, desligar-se de sua origem. O conhecimento que ele possuía vinha da experiência, tal como se nota em "À noite, depois dos negócios feitos, falava conosco geralmente sobre a chuva, as cheias, as árvores, as secas, a terra e os animais." (SALÚSTIO, 1999, p. 17)

Há, nesse conto, o contraste entre duas culturas: uma nativa, ligada à oralidade e à sabedoria popular, herança dos tempos coloniais, que não promovia a educação das classes menos favorecidas. A outra, letrada, que incorpora a língua do ex-colonizador como um elemento de emancipação política e social. Pela postura da narradora, tem-se o reconhecimento de que as duas culturas são válidas e possuem méritos, pois ela admite que a verdade não está em lado algum, o que interessa são as memórias.

O último grupo caracteriza-se pela violência (doméstica ou social): não há resolução para o conflito sem que a agressão apareça de alguma forma. Exemplos: "Foram as dores que o mataram"; "Filho de Deus nenhum"; "Para quando crianças de junho a junho".

O conto "Vinganças Crioulas" pode ser visto como uma alegoria da situação cabo-verdiana. Uma narradora homodiegética relata a história de Tony, criador de pombas. Ele foi chamado por uma mulher, desesperada com a situação do marido (à beira da morte). Ela necessitava fazer um remédio (feitiço), usando uma pomba estrangeira, pois foi dito a ela que assim seu marido seria curado. Tony tenta argumentar e diz:

[...] as estrangeiras não merecem a injúria de serem sacrificadas em ritos de feitiçaria, mesmo que a causa fosse a mais nobre possível, como eu acreditava ser o caso. Com as crioulas é diferente - tentei explicar-lhe - já estão habituadas a maus tratos e injustiças, além de que se reproduzem com muita facilidade, o que cá para nós, confidenciou, quase chega a ser pecado e nem mesmo se importam mais com as porradas dos machos, as suas gritarias e pressões selvagens. (SALÚSTIO, 1999, p. 77)

O que está sendo dito sobre as pombas, na verdade, serve para a antiga condição cabo-verdiana frente ao colonialismo português, pelo modo como os nativos eram vistos pelos "estrangeiros".

\section{CONSIDERAÇÕES FINAIS}

Percebemos, ao longo da obra, que há figuras femininas diferenciadas, representando um amplo apanhado de todas as classes sociais e de diferentes idades. A grande maioria das histórias é narrada em primeira 
pessoa, o que aproxima o leitor e também funciona como uma espécie de pedido de cumplicidade por parte das narradoras (que são a maioria no texto). A noite surge, em muitos enredos, como um símbolo de transformação, tendo em vista o subtítulo da obra: “... De como elas se entregam aos dias". Igualmente, constatamos a dubiedade do subtítulo, que pode tanto referir-se às noites (do título) como às personagens femininas representadas (e narradoras) nos contos.

A mudança dos narradores autodiegético e homodiegético caracteriza a viagem, pois as diferentes narradoras apresentam olhares sobre realidades contrastantes. A temática, recorrente na narrativa cabo-verdiana, pode ser vista nessas histórias. Os 35 contos do livro servem como um mapa humano de Cabo Verde. Ao apresentar vivências, Dina Salústio nos leva a uma (re)descoberta das ilhas. As histórias são exemplos do que a literatura tem a oferecer de representações de tipos humanos. Portanto, em Mornas eram as noites, "a viagem exprime um desejo profundo de mudança interior, uma necessidade de experiências novas, mais do que de um deslocamento físico." (CHEVALIER \& GHEERBRANT, 2000, p. 954). Dessa forma, finalizamos nossa viagem por Cabo Verde, guiados pela obra de Dina Salústio, com a sensação de termos conhecido um pouco mais sobre as ilhas, sua realidade e sua gente, principalmente as mulheres e sua condição!

\section{REFERÊNCIAS BIBLIOGRÁFICAS}

CALVINO, Italo. Por que ler os clássicos. São Paulo: Companhia das Letras, 1994.

CHEVALIER, Jean; GHEERBRANT, Alain. Dicionário de símbolos. Rio de Janeiro: José Olympio, 2000.

CIRLOT, Juan-Eduardo. Dicionário de símbolos. São Paulo: Editora Moraes, 1984.

CRISTÓVÃO, Fernando. Condicionantes culturais da literatura de viagens: estudos e bibliografias. Coimbra: Almedina, 2002.

FERREIRA, Manuel. Literaturas africanas de expressão portuguesa. São Paulo: Ática, 1987.

GOMES, Simone Caputo. Mulher com Paisagem ao Fundo: Dina Salústio Apresenta Cabo Verde. In: SEPÚLVEDA, Maria do Carmo; SALGADO, Maria Teresa. África \& Brasil: letras em laços. São Caetano do Sul: Yendis Editora, 2006.

. O conto de Dina Salústio: um marco na literatura cabo-verdiana. Idioma, $\mathrm{n}^{\circ} 25,2^{\circ}$ sem. de 2013, p. 52-70.

JÚDICE, Nuno. “A viagem entre o real e o maravilhoso" In: FALCÃO, Ana Margarida; NASCIMENTO, Maria Teresa; Leal, Maria Luísa (orgs.). 
Literatura de Viagem. Narrativa, história, mito. Lisboa: Edições Cosmos, 1997.

LAMAS, Estela Pinto Ribeiro. "A errância do mito ou o mito da errância no conto tradicional português". In: FALCÃO, Ana Margarida; NASCIMENTO, Maria Teresa; Leal, Maria Luísa (orgs.). Literatura de Viagem. Narrativa, história, mito. Lisboa: Edições Cosmos, 1997.

LARANJEIRA, Pires. Literaturas africanas de expressão portuguesa. Lisboa: Universidade Aberta, 1995.

LURKER, Manfred. Dicionário de simbologia. São Paulo: Martins Fontes, 1997.

MEIRELES, Cecília. Crônicas de viagem 2. Rio de Janeiro: Nova Fronteira, 1999.

SALGADO, Maria Teresa. Noites nada mornas de Dina Salústio: a oportunidade do diálogo. Abril, vol 1, n 1, ago.2008, p. 36-40.

SALÚSTIO, Dina. Mornas eram as noites... ...De como elas se entregam aos dias. Lisboa: Instituto Camões, 1999.

SANTILLI, Maria Aparecida. Literaturas de Língua Portuguesa: marcos e marcas - Cabo Verde: Ilhas do Atlântico em prosa e verso. São Paulo: Arte \& Ciência, 2007.

Recebido para publicação em 02/11/2015

Aprovado em 22/01/2016

\section{NOTAS}

* Professor Adjunto de Teoria Literária e Literaturas de Língua Portuguesa na Universidade Federal da Fronteira Sul (UFFS) - Campus Cerro Largo - RS. Este artigo apresenta uma parte da pesquisa de pós-doutorado "O conto africano de língua portuguesa em sala de aula" realizada na Universidade Federal do Rio Grande do Sul (UFRGS), sob supervisão da professora Márcia Ivana de Lima e Silva, em 2015. 